\title{
A MÁXIMA PROTEÇÃO SOCIAL E OS DIREITOS FUNDAMENTAIS: O CASO DA GRANDE INVALIDEZ NO REGIME PRÓPRIO DE PREVIDÊNCIA DO ESTADO DO RIO GRANDE DO NORTE
}

\author{
Melquiades Peixoto Soares Neto ${ }^{266}$ \\ Artur Cortez Bonifácio ${ }^{267}$
}

Recebido em: 15/12/2017

Aprovado em: 13/01/2018

\begin{abstract}
RESUMO
A proteção social é essencial para a garantia da igualdade no âmbito das relações entre indivíduos e entre estes e o Estado. Neste sentido, a Previdência Social, como elemento integrante da Seguridade Social, engendra o arcabouço protetivo do indivíduo frente aos mais diversos riscos na sociedade. Diante deste panorama, imperiosa a conferência de máxima efetividade destes direitos, pois relacionados com o mínimo existencial do indivíduo, sendo imprescindível para a garantia da igualdade. Assim, o presente trabalho, através de pesquisa bibliográfica analítica, objetiva demonstrar a necessidade da máxima proteção social e vedação de retrocesso, reconhecendo a aplicação direta da Constituição nos casos em que há omissão legislativa. Utiliza-se, como forma de demonstrar essa necessidade, o estudo da situação do adicional de invalidez na aposentadoria prevista em Regimes Próprios de Previdência, quando não há previsão expressa do referido adicional, demonstrando ser possível, através da aplicação da própria Constituição, a concessão deste direito aos segurados do RPPS.
\end{abstract}

Palavras-chave: Adicional por invalidez. Máxima Proteção Social. Previdência Social. Regime Próprio.

\section{INTRODUÇÃO}

A Seguridade Social é integrada pelo direito à Saúde, Assistência Social e Previdência Social, todos estes elementos se configurando como Direitos Fundamentais, que visam

\footnotetext{
266 Mestrando em Direito pela Universidade Federal do Rio Grande do Norte. Bacharel em Direito Pela Universidade Potiguar. Advogado.

${ }^{267}$ Doutor e mestre em Direito pela Pontifícia Universidade Católica de São Paulo. Professor Adjunto 4 de Direito Constitucional do mestrado e graduação no Departamento de Direito Público da UFRN. Juiz de Direito da $2^{\text {a }}$ Vara de Execução Fiscal do Estado do RN, Juiz Eleitoral do TRE-RN e membro cativo da Academia de Letras Jurídicas do RN.
} 
garantir a igualdade do indivíduo no plano material, lhe fornecendo um mínimo de dignidade para que possa integrar a sociedade e ter oportunidades de crescimento e desenvolvimento como cidadão.

No que se refere à Previdência Social, na Constituição de 1988, restaram elencados algumas situações tidas pela doutrina como "riscos sociais", os quais são objetos deste elemento da Seguridade Social, é dizer, são as situações em que a Previdência Social atua para garantir a dignidade do indivíduo afetado. Dentre os riscos, encontra-se a invalidez (Art. 201, I, da CF/88) ${ }^{268}$.

De ver-se que a proteção frente a esses riscos deve ocorrer com observância aos objetivos da seguridade social previstos no Art. 194, parágrafo único, da $\mathrm{CF} / 88^{269}$.

A Previdência Social abrange o sistema público, integrado pelo Regime Geral de Previdência Social - RGPS e pelo Regime Próprio de Previdência Social - RPPS, além do sistema privado, de natureza complementar e facultativa.

Diante do papel da $\mathrm{CF} / 88$, restou ao legislador infraconstitucional regular a prestação dos benefício previdenciários, no que tange ao sistema público (RGPS e RPPS).

Sendo o sistema público de filiação compulsória, não sendo facultado nem ao trabalhador, nem ao servidor público efetivo, não contribuir para os regimes, estabeleceu-se a problemática de vinculação destes indivíduos ao elenco de prestações conferidas pelas respectivas leis regulamentadoras.

Pois bem, a situação que se apresenta é a ausência de previsão na lei que regulamenta determinado Regime Próprio, no caso do Estado do Rio Grande do Norte, de prestação previdenciária estabelecida pelo Regime Geral, o que confere uma ausência de máxima proteção social aos respectivos servidores públicos efetivos vinculados. Para ilustrar a problemática, atendendo ao objeto deste artigo e observando-se a realidade, apresenta-se a

\footnotetext{
268 Art. 201. A previdência social será organizada sob a forma de regime geral, de caráter contributivo e de filiação obrigatória, observados critérios que preservem o equilíbrio financeiro e atuarial, e atenderá, nos termos da lei, a:

I - cobertura dos eventos de doença, invalidez, morte e idade avançada;

${ }^{269}$ Art. 194. A seguridade social compreende um conjunto integrado de ações de iniciativa dos poderes públicos e da sociedade, destinadas a assegurar os direitos relativos à saúde, à previdência e à assistência social.

Parágrafo único. Compete ao poder público, nos termos da lei, organizar a seguridade social, com base nos seguintes objetivos:

I - universalidade da cobertura e do atendimento;

II - uniformidade e equivalência dos benefícios e serviços às populações urbanas e rurais;

III - seletividade e distributividade na prestação dos benefícios e serviços;

IV - irredutibilidade do valor dos benefícios;

V- eqüidade na forma de participação no custeio;

VI - diversidade da base de financiamento;

VII - caráter democrático e descentralizado da gestão administrativa, com a participação da comunidade, em especial de trabalhadores, empresários e aposentados.
} 
situação específica do adicional de invalidez, também chamado de "complemento acompanhante", previsto no Art. 45 da Lei 8.213/91 ${ }^{270}$, no Regime Próprio de Previdência do Estado do Rio Grande do Norte, o qual visa conferir ao aposentado por invalidez um complemento da sua renda, quando se demonstra a necessidade, em face do seu estado incapacitante, do acompanhamento constante de outra pessoa.

A ausência de previsão legal na lei que regula o Regime Próprio do referido estado ocasiona a ideia equivocada de que os servidores públicos efetivos, quando titulares de aposentadoria, não fazem jus ao desfrute da referida prestação. Contudo, esta tese vai de encontro ao reconhecimento da máxima proteção social, bem como ao próprio texto constitucional, o qual prevê a proteção ao risco social da invalidez.

Para evidenciar o direito ao recebimento do adicional por invalidez no âmbito do Regime Próprio de Previdência do Estado do Rio Grande do Norte, será analisada a máxima proteção social, bem como a discussão acerca da matéria no âmbito jurisprudencial em situações onde a máxima proteção social integra a matéria de fundo, sem deixar de lado a previsão normativa na $\mathrm{CF} / 88$, na lei que regula o Regime Geral de Previdência Social (Lei 8.213/91) e na lei que regula o Regime Próprio de Previdência Social do Estado do Rio Grande do Norte.

\section{PREVISÃO NORMATIVA DO ADICIONAL POR INVALIDEZ NAS CONSTITUIÇÕES FEDERAL E ESTADUAL, NO REGIME GERAL DE PREVIDÊNCIA SOCIAL E NO REGIME PRÓPRIO DE PREVIDÊNCIA DO ESTADO DO RIO GRANDE DO NORTE}

Antes de adentrar na discussão de fundo, necessária se faz uma breve análise das legislações aplicáveis ao adicional por invalidez no âmbito constitucional e infraconstitucional, no que se refere ao RPPS do Estado do Rio Grande do Norte.

Como já mencionado anteriormente, dentre os riscos sociais elencados pela $\mathrm{CF} / 88$, os quais são objeto da Previdência Social, está a invalidez, nos termos do Art. 201, I.

\footnotetext{
${ }^{270}$ Art. 45. O valor da aposentadoria por invalidez do segurado que necessitar da assistência permanente de outra pessoa será acrescido de $25 \%$ (vinte e cinco por cento).

Parágrafo único. $\mathrm{O}$ acréscimo de que trata este artigo:

a) será devido ainda que o valor da aposentadoria atinja o limite máximo legal;

b) será recalculado quando o benefício que lhe deu origem for reajustado;

c) cessará com a morte do aposentado, não sendo incorporável ao valor da pensão.
} 
Em face da previsão constitucional, a Lei 8.213/91, a qual dispõe acerca do plano de benefícios no âmbito do Regime Geral de Previdência Social, em seu Art. 42, caput, estabelece o direito ao recebimento de aposentadoria por invalidez, quando o segurado “estando ou não em gozo de auxílio-doença, for considerado incapaz e insusceptível de reabilitação para o exercício de atividade que lhe garanta a subsistência, e ser-lhe-á paga enquanto permanecer nesta condição".

Por sua vez, o Art. 45 do mesmo diploma legal prevê a possibilidade de pagamento do adicional sobre a aposentadoria por invalidez, na situação em que o segurado necessitar de assistência permanente de outra pessoa, sendo o referido adicional equivalente a $25 \%$ (vinte e cinco) do valor do benefício de aposentadoria, podendo, inclusive, ultrapassar o valor do teto de pagamento do benefício.

No que se refere à Constituição do Estado do Rio Grande do Norte, a referida carta, em observância à CF/88, estabelece em seu Art. 130, I a proteção ao risco social da invalidez.

A norma que regula o Regime Próprio de Previdência do Estado do Rio Grande do Norte é a Lei Complementar $n^{\circ} 308 / 05$, que prevê o direito ao recebimento de aposentadoria por invalidez em seu Art. 44.

Contudo, em relação ao adicional de invalidez, não há previsão expressa na legislação estadual.

Feita esta breve análise, passa-se ao estudo do problema propriamente dito.

\section{MÁXIMA PROTEÇÃo SOCIAL E A GRANDE INVALIDEZ DIANTE DA OMISSÃO DA NORMA REGULAMENTADORA: APLICAÇÃO E LIMITES}

No estudo da máxima proteção social é essencial trabalhar três pontos específicos. O primeiro relacionado à historicidade dos Direitos Fundamentais, como forma de extrair o núcleo essencial de tais Direitos, é dizer, os mandamentos básicos a serem respeitados que, conforme será demonstrado, se espelham na liberdade e igualdade.

Em um segundo momento, o estudo parte para a análise propriamente dita da máxima proteção social, de forma direcionada para o caso apresentado, demonstrando a sua necessidade em face da interpretação constitucional e da efetividade dos Direitos Fundamentais, em especial quando se trata de risco social da invalidez.

Ademais, além de demonstrar a necessidade de aplicação da máxima proteção social, com base no núcleo dos Direitos Fundamentais, ou seja, dos valores da liberdade e igualdade, 
é necessário delimitar ou, melhor dizendo, construir, os limites de sua aplicação, ou seja, até onde o intérprete pode ir para reconhecer, garantir e efetivar um Direito Fundamental, sem que isso implique em uma invasão da atividade legiferante.

3.1 A historicidade dos Direitos Fundamentais e o seu núcleo de proteção: a essência da dignidade da pessoa humana

O risco social da invalidez está compreendido, conforme já exposto, no âmbito dos Direitos Fundamentais Sociais, por se caracterizar como fato gerado de uma prestação previdenciária específica, o benefício por incapacidade.

Neste aspecto, é primordial para a realização de um estudo acerca dos Direitos Sociais, que seja analisada a evolução do gênero ao qual esta categoria de direitos pertence, os Direitos Fundamentais. Neste sentido, a historicidade é elementar para a construção do conteúdo dos Direitos Sociais, evidenciando-se o panorama em que houve o seu reconhecimento e sistematização, bem como de onde adveio esta espécie, frente aos mais diversos anseios sociais e necessidades dos indivíduos da comunidade.

Este elemento, por sua vez, funciona como incidente para a extração do conteúdo essencial dos Direitos Sociais, externado na dignidade humana, mas que se instrumentaliza por meio da liberdade e igualdade.

Os Direitos Fundamentais não advieram de uma ação imediata, de uma ruptura dogmática em absoluto, mais de um processo de evolução constante, de um progresso pensante, de geração para geração, havendo interdependência e complementação no seu procedimento de evolução, até chegarmos até o momento atual.

Muito bem, é essencial ter em mente que os Direitos Fundamentais tem o seu surgimento sob a base da limitação da atuação do Estado, retirando deste ente abstrato a prerrogativa de limitação ordinária da vida do indivíduo, passando-se para uma função de observador e gerenciador social, ou seja, dando ao súdito o direito mínimo de controle da sua própria vida, obedecendo um ordenamento de deveres básicos para não haver ofensa aos direitos dos demais integrantes da sociedade. Além da abstenção do Estado, os Direitos Fundamentais atribuem ao ente estatal um dever de prestação positiva, com base em uma atuação social, sob o pilar da igualdade material e da dignidade humana. Diante deste conteúdo essencial dos Direitos Fundamentais, ou melhor, da sua finalidade, passa-se a análise histórica propriamente dita. 
Os Direitos Fundamentais partem de uma ideia de racionalidade do homem, como ser incompleto, buscando sua completude com a vivência real, construindo-se e descontruindo-se a partir dos seus sentidos e da linguagem, em um processo evolutivo constante e dinâmico, mudando a si mesmo e o ambiente onde vive. Sendo assim, o homem vira o objeto de estudo do próprio homem, eleva-se a razão acima da divindade e, pela primeira vez, a crença é ultrapassada para um viés filosófico. Desenvolve-se o conceito mais ético do que divino, causando uma aproximação entre os homens e o desenvolvimento e disseminação do conhecimento. A este período, compreendido entre os séculos VIII a II a.C., atribui-se a terminologia de "período axial" (COMPARATO, 2013, p. 14).

$\mathrm{Na}$ antiguidade greco-romana, ainda que houvesse o entendimento de igualdade entre os homens, como direito fundamental, não se atribuía essa igualdade em um patamar material, mas apenas formal e, ainda, não se aplicava este direito em favor de todos os membros da sociedade, mas apenas de uma parte privilegiada, sendo prevalente a escravidão e divisão em castas: "somente os cidadãos da Pólis podiam usufruir da igualdade perante o direito (Isonomia), da mesma liberdade da palavra (Isogoria) e do mesmo respeito (Isotomia)" (CARVELLI; SCHOLL, 2011, p. 169). Contudo, apesar desta ideia geral, defendia-se a existência de um direito natural à igualdade, o qual não poderia ser sobreposto pelo direito posterior, não sendo por este derrogado ou modificado. Por sua vez, este direito natural decorria da essência do homem, isto é, do seu interior, independentemente da carcaça, o que tornava a igualdade aplicável a todos os indivíduos dos mais diversos povos, independentemente de nacionalidade, raça, sexo, cultura etc.

A lei (nomos) tinha papel fundamental nas ações estatais, sendo que a sua existência e a participação popular na atuação do Estado eram os pilares do governo ateniense no século $\mathrm{V}$ a.C.. Além disso, o governo tinha ampla participação popular, com o julgamento dos crimes mais graves praticados pelos Governantes pelo próprio povo, em assembleias (Ekklésia), além do controle exercido por este através da formulação de ações ou denúncias pela infração da lei ou mesmo da inobservância da constituição da Cidade (politeia).

Já a República Romana teve êxito na limitação dos poderes estatais por meio da complexidade do seu sistema de divisão governamental, integrado pelos Cônsules, pelo Senado e Pelo povo. Os primeiros exercendo o poder Monárquico, os segundos o poder Aristocrático e os terceiros o Poder Democrático, em junção dos regimes políticos ditados por Aristóteles e Platão.

De ver-se que, historicamente, a ideia inicial de necessidade dos Direitos Fundamentais se deu entre os séculos XI a X a.C., com o reino unificado de Israel, sob o 
comando de David. Diferentemente dos governos absolutos da época, David vinha não como o monarca absoluto que ditava as leis para legitimar o seu poder sobre os súditos, mas como o governante que se submetia às leis divinas, as quais pregavam a humanidade e limitação, ainda que protótipa, dos poderes do rei (COMPARATO, 2013, p. 36).

Embora houvesse este pensamento inicial de igualdade, advindo de um estado natural, anterior à constituição da própria sociedade, o que ocasionava uma impossibilidade de prevalência do direito vigente em relação a esta prerrogativa natural, a legislação grega e romana não trazia previsões de Direitos Fundamentais, os quais serviriam como limitadores da atuação estatal. Ironicamente, a ausência de limitação do poder do Estado, por meio dos Direitos Fundamentais, foi o que motivou o surgimento destes, desenvolvendo uma visão do ente estatal como inimigo precípuo da liberdade do cidadão (BONAVIDES, 2007, p.40).

Na Idade Média, o Cristianismo teve um papel decisivo para a construção de um conceito do Direito integrado por valores subjetivos, como a moral. As determinações inseridas pela religião no Direito influíram na configuração de um ideal de liberdade e igualdade dos homens perante Deus, pois são a semelhança deste. Desenvolve-se, ainda, no período medieval, um juízo de adequação entre a determinação natural de igualdade e as determinações posteriores, racionalmente inseridas pelo homem na sociedade, de forma que a incompatibilidade da norma posterior ocasionaria a sua exclusão.

O desenvolvimento deste conceito de pessoa humana ganha alargamento com o pensamento de Kant, com a ideia de que somente a pessoa, como ser racional, é capaz de se submeter a todas as leis que dela mesma partem, sendo um fim em si mesmo e fonte de onde emanam tais determinações. Ademais, para o alcance ético, é imperiosa a consideração não só do alcance da felicidade própria mas, sendo a comunidade humana um fim em si mesmo, é imperioso o reconhecimento da felicidade alheia, saindo-se de um juízo puramente de abstenção, no sentido de não prejudicar ninguém, para um juízo de importância do outro (KANT, 2013, p. 42).

O ser humano é o único ser capaz de guiar a suas ações a partir de valores, desenvolvidos com a relação com outros indivíduos e com objetos, sendo os Direitos Fundamentais direcionados à defesa e garantia destes valores mais relevantes para a personalidade.

Contudo, a cedência da soberania popular (governo ateniense) e do complexo sistema de controle do poder governamental, pela iniciação dos governos imperiais de Alexandre Magno, a partir do século IV a.C., faz surgir o início da Idade Média. Inicialmente, em especial pelos valores clássicos e cristãos a semente da proteção e garantia da liberdade do 
indivíduo se manteve viva, contudo, o seu desenvolvimento sofreu um sério retrocesso diante do surgimento do feudalismo.

Contudo, o desrespeito à liberdade e propriedade engendraram as primeiras manifestações contrárias ao regime autoritário partido do sistema feudal, que foram as Declarações da Corte de Leão de 1188 e a Magna Carta de 1215.

A partir do século XVII, viveu-se um período de profunda construção do Estado absoluto, principalmente pelos ideais de Thomas Hobbes e Jean Bodin. Essa construção serviu de base para a fundamentação do ideal liberal do século seguinte, que culminou no desenvolvimento do Estado abstencionista e no aperfeiçoamento da igualdade formal.

Então, percebeu-se que o papel de abstensão estatal em um patamar quase que absoluto, como forma de preservar a igualdade formal, tida como a grande conquista dos movimentos liberais, culminava, ironicamente, em um processo de desigualdade dos indivíduos, na medida em que a exploração do trabalho e as desigualdades econômicas não sofriam qualquer interferência do Estado como forma de buscar uma igualdade material.

Por outro lado, as atrocidades ocorridas pelas duas grandes Guerras Mundiais culminaram em um volvimento do Direito para o ser humano, para a garantia de um mínimo existencial e pela preservação da dignidade. Somente por meio da intervenção estatal seria possível alcançar um patamar mínimo de igualdade entre os sujeitos, permitindo que aqueles em que a própria sociedade não conferia oportunidades ou mesmo instrumentos de crescimento, poderiam, através do Estado, ter o impulso mínimo para se dignificar e galgar novos passos no meio social, até alcançar um status de autonomia e auxiliar os novos necessitados.

Portanto, percebe-se que a essência de um direito social, seja qual for, parte de um intrincado equilíbrio entre a liberdade e a igualdade. A liberdade no sentido de não sofrer interferências estatais abusivas que atinjam a sua esfera jurídica, limitando, portanto, o seu crescimento e desenvolvimento como integrante de um meio social, e igualdade tanto no espaço formal, como material, não só garantindo a não interferência do Estado, mas também garantindo a sua inserção na sociedade, como agente social, para trabalhar com as desigualdades ocasionadas por esta liberdade pura, fornecendo os meios e garantias de preservar uma sociedade igualitária no plano material, através da função social, solidariedade e boa-fé dos indivíduos.

Neste ponto é que a máxima proteção social deve se pautar, considerando esta essência do Direito Social à proteção da contra a invalidez, considerando não só a liberdade do cidadão, mas também a igualdade nos diversos níveis em que essa invalidez pode ocorrer. 
3.2 A máxima proteção social aplicada ao risco social da invalidez: necessidade de norma expressa e abrangência da proteção

Logo de início é necessário lembrar que tanto a aposentadoria por invalidez, como o adicional referido, são Direitos Fundamentais Sociais, vinculados a tutela previdenciária do Estado em face de um risco social, no caso, a invalidez.

Neste sentido, imperiosa a constatação de que os Direitos Fundamentais possuem aplicabilidade imediata, independendo de qualquer atuação posterior, no sentido de norma regulamentadora infraconstitucional, para que sejam aplicáveis. Observe-se a redação do Art. $5^{\circ}, \S 1^{\circ}$ da $\mathrm{CF} / 88$ : “as normas definidoras dos direitos e garantias fundamentais têm aplicação imediata".

Pois bem, diante deste elemento, evidencia-se que, tratando-se de Direitos Fundamentais, não há que se falar em impossibilidade de aplicação por ausência de lei regulamentadora, exceto nas situações em que a própria Constituição limita a aplicação do referido direito, através da abertura de interferência de uma lei regulamentadora, que venha a limitar os efeitos (norma constitucional de eficácia contida) (DA SILVA, 2001, p. 115).

Ademais, o direito ora tratado vincula-se diretamente ao princípio da dignidade da pessoa humana, visando garantir meios de subsistência do segurado da Previdência Social em face do risco social da invalidez, velhice e inatividade. É dizer, garante-se ao indivíduo que não possui meios de auferir renda através do trabalho, diante do seu estado incapacitante, uma renda mínima que lhe auxilie na sua subsistência e na subsistência da sua família.

Em brilhante lição acerca dos papéis desempenhados pelos princípios em um ordenamento jurídico, referindo-se especificamente ao princípio da Dignidade da Pessoa Humana, Luís Roberto Barroso nos ensina que:

Esse é o primeiro papel de um princípio como a dignidade humana: funcionar como uma fonte de direitos - e, consequentemente, de deveres —, incluindo os direitos não expressamente enumerados, que são reconhecidos como parte das sociedades democráticas maduras.

O outro papel principal da dignidade humana é interpretativo. A dignidade humana é parte do núcleo essencial dos direitos fundamentais, como a igualdade, a liberdade ou o direito ao voto (o qual, a propósito, não está expresso no texto da Constituição dos Estados Unidos). Sendo assim, ela vai necessariamente informar a interpretação de tais direitos constitucionais, ajudando a definir o seu sentido nos casos concretos. Além disso, nos casos envolvendo lacunas no ordenamento jurídico, ambiguidades no direito, colisões entre direitos fundamentais e tensões entre direitos e metas coletivas, a dignidade humana pode ser uma boa bússola na busca da melhor solução. Mais ainda, qualquer lei que viole a dignidade, seja em abstrato ou em concreto, será nula (BARROSO, 2014, p. 67). 
Sendo um princípio, a dignidade da pessoa humana possui a finalidade precípua de mandamento de otimização, no sentido de tornar cada vez mais efetiva a norma jurídica, seja ela uma regra, seja outro princípio. Conforme estabelece Robert Alexy:

\begin{abstract}
Normas-princípios são mandamentos de otimização, que podem ser satisfeitos em graus diversos, e cuja medida devida de satisfação não depende apenas e as possibilidades fáticas, mas também pelas possibilidades jurídicas. Elas têm uma tendência normativa à otimização, sem se fixar, no entanto, em um conteúdo determinado; elas são - necessariamente - passíveis de serem sopesadas.

(...)

Como mandamentos de otimização, princípios exigem uma realização mais ampla possível em face não apenas das possibilidades fáticas, mas também em relação às possibilidades jurídicas (ALEXY, 2015, p. 577).
\end{abstract}

Essa conclusão fundamenta a natureza das normas-princípio, as quais têm a função não só de aplicação propriamente dita, mas também a possibilidade de otimização, senão maximização, do ordenamento jurídico, em um plano de efetividade.

Percebe-se, assim, que a Dignidade da Pessoa Humana funciona como um elemento latente na aplicação dos Direitos Fundamentais, diante da impossibilidade da lei abarcar de forma absoluta todas as situações concretas que necessitam da proteção fundamental de tais direitos, permitindo uma elasticidade e volatilidade das normas expressas, com a construção de novos campos de proteção por meio de uma atividade interpretativa, esta tendência vem sendo conferida mundialmente em uma construção doutrinária e jurisprudencial internacional (BARROSO, 2014, p. 70).

Na proteção dos Direitos Fundamentais, especificamente na ordem constitucional brasileira, como vem reconhecendo a Suprema Corte em diversas ocasiões, a dignidade humana possui um papel de evidência na ampliação da eficácia dos referidos direitos, os quais não implicam apenas em um dever de abstenção do Estado, como forma de repelir eventuais ofensas decorrentes da atividade estatal, frente aos indivíduos, ou mesmo entre estes (eficácia horizontal), o que foi fruto do constitucionalismo liberal, mas também implica no dever de legislar e ampliar a eficácia das normas, através de uma atividade interpretativa, como forma de construir um ambiente de máxima efetividade dos Direitos Fundamentais, o que é fruto da atuação social do Estado, como intervencionista na sociedade para proteger e construir um ambiente de igualdade material. Assim, a atuação estatal no sentido de observância dos Direitos Fundamentais Individuais, os quais exigem uma abstenção estatal, não devem ofuscar a atuação positiva do Estado, no que se refere aos Direitos Fundamentais Sociais (BONAVIDES, 1997, p. 569). 
Neste sentido, o STF na Reclamação Constitucional $n^{\circ}$ 4.374/PE, quando analisou a constitucionalidade do Art. 20, $\S 3^{\circ}$, da Lei 8.742/93, que delimita o critério objetivo de aferição da miserabilidade, para fins de concessão do benefício assistencial de prestação continuada ao deficiente, previsto no Art. 201, V, da CF/88, reconheceu a insuficiência de tal critério, diante das diversas mudanças fáticas e sociais ocorridas no plano material. De ver-se que, em sua fundamentação, o Pretório Excelso reconheceu a necessidade de combater um estado de proteção insuficiente do direito fundamental, de forma a garantir a máxima efetividade, visando sempre o estabelecimento de uma situação de igualdade material.

Destacou o Relator, Ministro Gilmar Mendes que não se trata de suprimento de omissão legislativa, propriamente dita, por parte do Poder Judiciário, mas sim de observância de um estado de insuficiência da lei regulamentadora, ou seja, quando a lei existe, contudo, é insuficiente para suprir a necessidade de proteção que demanda no caso concreto:

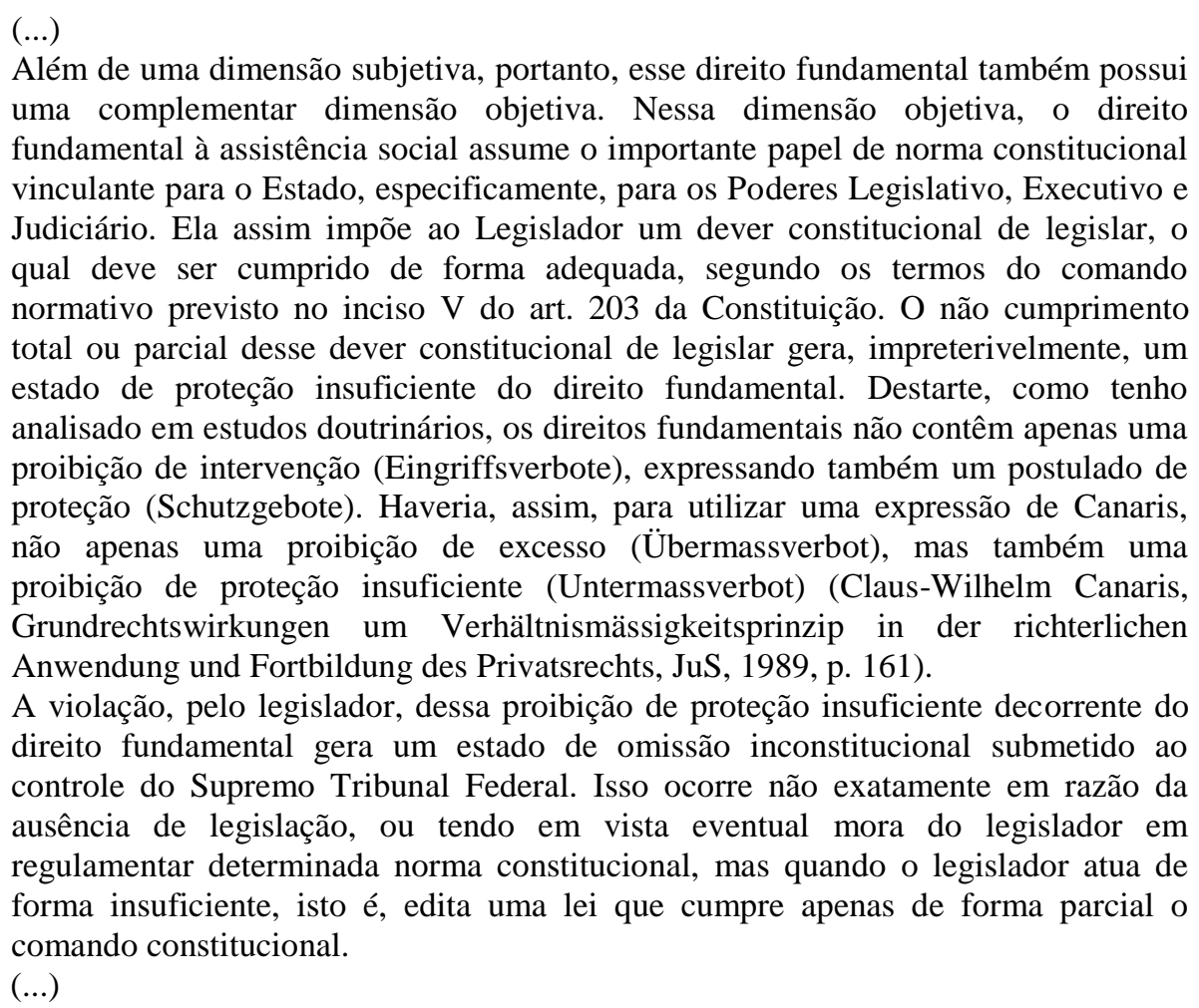

No que se refere aos riscos sociais, o Art. 201 da CF/88 estabelece o seguinte:

(...)

Art. 201. A previdência social será organizada sob a forma de regime geral, de caráter contributivo e de filiação obrigatória, observados critérios que preservem o equilíbrio financeiro e atuarial, e atenderá, nos termos da lei, a: (Redação dada pela Emenda Constitucional $n^{\circ} 20$, de 1998)

I - cobertura dos eventos de doença, invalidez, morte e idade avançada; (Redação dada pela Emenda Constitucional no 20 , de 1998).

(...) 
Essa redação é integralmente acolhida pelo Art. 130, I da Constituição do Estado do Rio Grande do Norte.

Assim, percebe-se que o objetivo do constituinte foi garantir ao indivíduo uma proteção mínima frente aos mais diversos riscos sociais, de forma a preservar a sua dignidade em um plano de efetividade máximo, através de prestações ativas estatais, configurados por meio do pagamento de benefícios previdenciários. Este é o comando constitucional.

Destaca-se, ainda, o fato de que o Brasil é signatário da Convenção Internacional sobre os Direitos das Pessoas com Deficiência promulgado pelo Decreto Presidencial $\mathrm{n}^{\circ}$ 6.949 , de 25 de agosto de 2009, após a aprovação pelo Congresso Nacional, por meio do Decreto Legislativo ${ }^{\circ} 186$ de 09 de julho de 2008, com status de Emenda Constitucional, na forma do Art. $5^{\circ}, \S 3^{\circ}$, da $\mathrm{CF} / 88$. A referida norma constitucional dispõe em seu preâmbulo a necessidade de promover e proteger os direitos humanos de todas as pessoas com deficiência, inclusive daquelas que requerem maior apoio.

Ainda, em seu Artigo 5, item 1, estabelece a necessidade de igualdade em relação a pessoas com deficiência:

1.Os Estados Partes reconhecem que todas as pessoas são iguais perante e sob a lei e que fazem jus, sem qualquer discriminação, a igual proteção e igual benefício da lei.

No que se refere a possibilidade de integração de novos direitos ao rol de Direitos Fundamentais estabelecido na $\mathrm{CF} / 88$, é imperioso destacar que a referida incorporação como norma constitucional só se efetiva diante de um Tratado Internacional que verse sobre Direitos Humanos. Ademais, o rol de direitos estabelecidos no texto constitucional pátrio é meramente exemplificativo, permitindo ampliação de acordo com as normas internacionais incorporadas (BONIFÁCIO, 2008, p. 209).

Além disso, inobstante não expresso, um Direito Fundamental pode decorrer, implicitamente, de uma norma constitucional positivada e expressa, o que não deixa de ser uma ampliação do rol previsto. Trata-se do sentido material dos Direitos Fundamentais (BONIFÁCIO, 2008, p. 79).

De forma mais incisiva, em seu Artigo 28, a Convenção Internacional referida atesta a necessidade de garantia não somente da vida da pessoa que possua algum impedimento que gere deficiência, mas também que seja garantido o mínimo existencial, refletido no estabelecimento de um padrão de vida digno, com o suprimento das necessidades básicas da pessoa com deficiência e da sua família:

1.Os Estados Partes reconhecem que todas as pessoas são iguais perante e sob a lei e que fazem jus, sem qualquer discriminação, a igual proteção e igual benefício da lei. 2.Os Estados Partes reconhecem o direito das pessoas com deficiência à proteção social e ao exercício desse direito sem discriminação baseada na deficiência, e tomarão as medidas apropriadas para salvaguardar e promover a realização desse direito, tais como:

(...)

c) Assegurar o acesso de pessoas com deficiência e suas famílias em situação de pobreza à assistência do Estado em relação a seus gastos ocasionados pela 
deficiência, inclusive treinamento adequado, aconselhamento, ajuda financeira e cuidados de repouso;

(...)

e) Assegurar igual acesso de pessoas com deficiência a programas e benefícios de aposentadoria.

Assim, reconhece-se a possibilidade do surgimento de novos impedimentos além dos impedimentos gerados pela invalidez que ocasionou a proteção inicial do Estado sendo que, havendo agravamento do quadro, sem dúvidas, cabe ao ente estatal fornecer os meios de suprir o impedimento agravado, ocasionando um ambiente de igualdade material, com observância direta da dignidade da pessoa humana.

Portanto, é imperioso reconhecer que o fato de existir um risco social não abrangido de forma expressa pela norma constitucional, não implica na ausência de obrigação do Estado em garantir ao indivíduo a respectiva proteção, pois, embora haja regulação expressa, as norma constitucionais que estabelecem a Previdência Social decorrem da dignidade da pessoa humana, o que permite uma ampliação da aplicação de tais normas às mais diversas situações que ofendam o referido princípio (SAVARIS, 2010, p. 200).

Trata-se, a rigor, da expressão da proibição do retrocesso, o que ocorre a partir da preservação dos níveis de segurança social espelhados nos Direitos Fundamentais sociais, a partir de uma observação retrospectiva e prospectiva da atividade legislativa, que deve, em ambos os casos, preservar a segurança e proteção conferido por tais direitos. De ver-se que a proibição não incide somente a partir de legislação que suprime direitos ou os limita a partir de políticas econômicas em detrimento de políticas públicas, mas sua incidência abrange, outrossim, a interpretação da norma constitucional de onde deflui a proteção social defendida (MIRANDA, 2000, p. 351). Não cabe, portanto, ao legislador infraconstitucional, com base na alegação de crise ou política econômica, suprimir a determinação legal que regula norma constitucional garantidora de determinado direito, pois isso se configuraria na destruição da própria situação instaurada pelo legislador (MIRANDA, 2000, p. 397).

Na cristalina lição de Luiz Roberto Barroso, acerca da proibição do retrocesso, “entende-se que se uma lei, ao regulamentar um mandamento constitucional, instituir determinado direito, ele se incorpora ao patrimônio jurídico da cidadania e não pode ser absolutamente suprimido" (2001, p. 158).

A obrigação do Estado de garantir a cobertura dos mais diversos riscos sociais surgidos na comunidade, estejam eles expressos no texto constitucional ou não, decorre da necessidade de universalidade da cobertura e do atendimento, como objetivo expresso da 
Seguridade Social, a qual compreende a Saúde, a Previdência e a Assistência Social, estando expressa no Art. 194, I, da CF/88 271 e no Art. 123, I, da Constituição Estadual ${ }^{272}$.

Um exemplo de incremento da proteção social das pessoas que possuem impedimentos incapacitantes, relacionados ao estado de saúde, com base justamente na norma constitucional supracitada, é a possibilidade de redução da carência e tempo de contribuição no caso de aposentadoria de pessoas com deficiência, a qual restou regulada por meio da Lei Complementar $\mathrm{n}^{\circ} 142$ de 08 de maio de 2013, a qual regulamentou o disposto no Art. 201, $\S 1^{\circ}$, da $\mathrm{CF} / 88$, no tocante à aposentadoria da pessoa com deficiência segurada do Regime Geral de Previdência Social - RGPS.

De ver-se que o Art. 40, $\S 2^{\circ}$, I, da CF/88 também prevê a possibilidade de concessão de aposentadoria com critérios diferenciados para pessoas portadoras de deficiência, no âmbito do RPPS, benefício este que será regulamentado por meio de lei complementar ${ }^{273}$. A lei complementar referida ainda não foi editada pelo Poder Legislativo, sendo que, sem dúvidas, o exercício deste direito não resta impedido pela ausência da norma regulamentadora, sendo imperioso o reconhecimento da aplicação subsidiária da Lei Complementar 142/2013 no âmbito dos RPPSs.

O que quer se demonstrar, é que não existe proibição de extensão das normas reguladoras do RGPS no âmbito dos RPPSs, desde que esta regulamentação seja exigida constitucionalmente, ou mesmo haja norma constitucional que implique na necessidade de proteção, pelo Estado, do indivíduo em relação aos riscos sociais, como ocorre no presente caso.

Tanto é assim que a Lei 9.717/98 a qual estabelece regras gerais para a organização e o funcionamento dos regimes próprios de previdência social dos servidores públicos da União, dos Estados, do Distrito Federal e dos Municípios, dos militares dos Estados e do Distrito

\footnotetext{
${ }^{271}$ Art. 194. A seguridade social compreende um conjunto integrado de ações de iniciativa dos Poderes Públicos e da sociedade, destinadas a assegurar os direitos relativos à saúde, à previdência e à assistência social.

Parágrafo único. Compete ao Poder Público, nos termos da lei, organizar a seguridade social, com base nos seguintes objetivos:

I - universalidade da cobertura e do atendimento;

${ }^{272}$ Art. 123. A seguridade social compreende um conjunto integrado de ações de iniciativa dos Poderes Públicos e da sociedade, destinadas a assegurar os direitos relativos à saúde, à previdência à assistência social. Parágrafo único. Compete ao Poder Público, nos termos da lei, organizar a seguridade social, com base nos seguintes objetivos:

I - universalidade da cobertura e do atendimento;

${ }^{273}$ Art. 40.

(...)

$\S 4^{\circ}$ É vedada a adoção de requisitos e critérios diferenciados para a concessão de aposentadoria aos abrangidos pelo regime de que trata este artigo, ressalvados, nos termos definidos em leis complementares, os casos de servidores: (Redação dada pela Emenda Constitucional no 47, de 2005)

I portadores de deficiência; (Incluído pela Emenda Constitucional nº 47, de 2005).
} 
Federal não veda a equiparação entre o RGPS e o RPPS, proibindo apenas a instituição de benefício que não possua previsão no RGPS:

Art. $5^{\circ}$ Os regimes próprios de previdência social dos servidores públicos da União, dos Estados, do Distrito Federal e dos Municípios, dos militares dos Estados e do Distrito Federal não poderão conceder benefícios distintos dos previstos no Regime Geral de Previdência Social, de que trata a Lei no 8.213, de 24 de julho de 1991, salvo disposição em contrário da Constituição Federal.

Assim, o legislador vedou a possibilidade de instituição de benefícios diversos daqueles previstos para o RGPS (Lei 8.213/91), exceto nos casos onde houver expressa disposição constitucional.

Por sua vez, a CF/88, independentemente dos benefícios previstos no RPPSs, determinou a necessidade de máxima adequação, no que couber, entre os RPPSs e o RGPS, na forma do Art. 40, §12:

\footnotetext{
Art. 40. (...)

(...)

$\S 12$ - Além do disposto neste artigo, o regime de previdência dos servidores públicos titulares de cargo efetivo observará, no que couber, os requisitos e critérios fixados para o regime geral de previdência social. (Incluído pela Emenda Constitucional no 20, de 15/12/98).
}

Esta previsão constitucional visa conferir, de forma materialmente igualitária, a proteção dos indivíduos submetidos aos dois regimes de previdência, uma vez que a finalidade e o objeto de ambos, são iguais.

Não é a primeira vez em que se busca a ampliação de um direito reconhecido aos segurados do RGPS, em prol dos segurados do RPPS. Na jurisprudência do Supremo Tribunal Federal tem-se o caso do direito à aposentadoria especial do servidor público, o qual vinha sendo rejeitado pelo Estado sob a justificativa de inexistência de lei regulamentadora, mesmo diante de previsão constitucional que garantia ao servidor tal direito (Art. 40, §4 $4^{\circ}$, da $\mathrm{CF} / 88$ ). $\mathrm{Na}$ análise do caso em referência, o STF entendeu ser possível a aplicação das normas referentes ao RGPS, que regulam a aposentadoria especial dos respectivos segurados, ao RPPS, enquanto não for editada a lei regulamentadora, justamente pelo fato de que a aposentadoria especial revela-se como um Direito Fundamental e, portanto, possui aplicação imediata (MI 758/DF, Plenário, STF, Rel. Min. Marco Aurélio, julg. 01/07/2008). A reafirmação deste entendimento, veio por meio do MI Coletivo 4.475/DF.

Após reiterados julgamentos no mesmo sentido, com a consolidação do posicionamento do STF, a Suprema Corte editou a súmula vinculante $n^{\circ} 33$, com a seguinte redação: 
Aplicam-se ao servidor público, no que couber, as regras do regime geral da previdência social sobre aposentadoria especial de que trata o artigo 40 , $\S 4^{\circ}$, inciso III da Constituição Federal, até a edição de lei complementar específica.

Destaca-se neste posicionamento do Supremo a aplicação da teoria concretista no Mandado de Injunção, permitindo que o Judiciário, reconhecendo a omissão inconstitucional, possa proferir uma decisão socialmente efetiva, não só reconhecendo a omissão em si, mas suprindo-a, de uma forma a não invadir a atividade legiferante, com ofensa à Separação dos Poderes. Neste sentido, o STF apenas reconheceu a existência e aplicabilidade imediata do direito objeto da discussão, permitindo a sua efetividade por meio do suprimento da ausência de regulamentação, com a aplicação das normas do RGPS, também atendo a máxima integração entre os regimes, bem como ao suprimento subsidiário exercido pelo RGPS, nos termos do Art. 40, §12, da CF/88.

Em outra oportunidade, o STF debruçou-se sobre uma situação em que norma estadual que instituiu RPPS criava requisito não previsto nem na norma constitucional, nem na norma que regula o RGPS, para fins de concessão de pensão por morte, no caso, a invalidez do dependente do instituidor. Como se sabe, no RGPS é estabelecida a possibilidade de concessão de pensão por morte aos dependentes do falecido, desde que se comprovem dois requisitos, quais sejam, qualidade de segurado do falecido(a) e condição de dependente de quem requer a pensão, na forma do Art. 16 da Lei 8.213/91. Contudo, a lei estadual discutida no julgamento do STF criou um requisito a mais, a invalidez do dependente. A solução aplicada pelo STF foi justamente no sentido de reconhecer a aplicação subsidiária das normas do RGPS em face do RPPS, entendo como inconstitucional a exigência criada pela lei estadual (AgR. RE 385.397-0/MG, STF, Plenário, Rel. Min. Sepúlveda Pertence, p. 612, julg. 29/06/07).

Os Direitos Fundamentais, neste sentido, não se limitam a conferir direitos subjetivos ao indivíduo, mas também expressam valores objetivos, o que irradia os efeitos das respectivas normas para a interpretação nos mais diversos ramos do Direito, os quais devem, sempre na sua aplicação, observar esta carga valorativa. Esta necessidade de afastamento de uma concepção minimalista dos Direitos Fundamentais decorreu das atrocidades ocorridas especialmente após a 2a Guerra Mundial (GRIMM, 2007, p. 154).

Decorre desta conclusão, que os Direitos Fundamentais engendram não só uma proibição de excesso, no caso do legislador, mas também uma proibição de proteção insuficiente, ou seja, quando, mesmo havendo previsão normativa de garantia de um determinado Direito Fundamenta, este é violado diante da proteção insuficiente conferida pela 
respectiva norma. Na primeira hipótese o legislador vai longe demais, enquanto na segunda o legislador faz pouco, tornando insuficiente a proteção (GRIMM, 2007, p. 149).

Portanto, a máxima proteção social advém da vedação da proteção insuficiente dos Direitos Fundamentais, no sentido de que deve-se conferir efetividade em grau máximo a tais direitos, de forma a garantir a igualdade material almejada pela reaproximação entre os Direitos Fundamentais Sociais e Individuais.

\subsection{Limites à aplicação da máxima proteção social}

É evidente que a possibilidade de aplicação da norma constitucional que protege o indivíduo de um risco social, de forma a abarcar situações que não decorrem diretamente do texto não é ilimitada.

Ao encontrar o efeito da norma que abrange a situação pretendida, o intérprete já extrai do texto um elemento não expresso, através da consideração sistêmica do ordenamento, bem como da inserção de valores sociais na análise dos efeitos. Essa admissão de abertura é essencial para que se fuja de um modelo arcaico e ultrapassado de aplicação estagnada da norma, sem a evolução dos seus efeitos, sem a necessidade de modificação do texto.

A inadmissão da inserção deste valores acaba por constituir a atividade hermenêutica a partir de um constitucionalismo meramente formalista, de índole procedimental, sob o manto de uma pseudoneutralidade. Por outro lado, deve-se considerar, na análise da norma imposta pelo constitucionalismo moderno, a consideração de elementos (dimensões) textuais, reais e ideológicos. Os elementos de ordem textual, dizem respeito aos que o intérprete tem o primeiro contato quando parte para a análise efetiva da norma; os elementos reais abrangem o domínio fático do Direito e sua interpretação; já os elementos ideais (ideológicos) considera a precompreensão do intérprete acerca do direito analisado (SCHIER, 1997, p.40).

Percebe-se, assim, pelo afirmado anteriormente, que a norma considera elementos anteriores ao próprio texto, que partem da compreensão prévia do intérprete, além do que as consequências da norma e de sua aplicação são consideradas no processo interpretativo, pois relevantes para definir o real sentido do objeto interpretado. Esta consideração de elementos ideológicos, reais e textuais fundamenta a atribuição de uma força normativa à Constituição (HESSE, 1991, p. 34).

O Constitucionalismo, desta forma, na pós-modernidade, tem o papel de observância da dignidade humana, de forma a limitar as liberdades individuais ao mesmo tempo em que as garante, em respeito à comunidade. Assim, não visa somente a criação de direitos subjetivos a 
partir dos direitos fundamentais, mas sim o respeito e crescimento social, harmonizando o indivíduo e a comunidade (COELHO, 2005, p. 09)

É justamente esta materialização da interpretação, saindo de um mero formalismo, para considerar a realidade posta, que evidencia a "Constituição Real” (LASSALE, 1985, p.49). Não basta a existência da norma se não houver a sua adequação à realidade que, muitas vezes, prescinde de uma edição de norma nova, apenas evidenciando a interpretação com a consideração de todos os elementos referidos, para que haja correspondência entre a norma constitucional e a realidade.

A própria metodologia de interpretação abrange uma relação de verticalidade entre a norma e o intérprete. O aplicador da lei busca em seu objeto (a norma) o sentido e o alcance de sua aplicação, em uma relação verticalizada quem, em muitos casos, se configura em verdadeira relação de hierarquia. Trata-se da aplicação de um modelo dedutivo ou lógico formal. É preciso vencer este modelo, pois não só da lei o intérprete, no processo hermenêutico, retira os fundamentos do sentido e alcance da norma (CHAVES, 2017, p. 153). Este posicionamento do intérprete no processo hermenêutico privilegia um entendimento de um legislador infalível (CHAVES, 2017, p. 158), o que esbarra na evolução da sociedade e no surgimento de novas tecnologias, o que demanda uma confecção de novo sentido à lei, para se adequar a realidade social, sob pena de inserir-se em um papel de ineficácia.

Que a interpretação efetiva deve considerar algo além do formalismo e da depuração absoluta de valores sociais e reais, resta claro, contudo, até onde o intérprete pode ir para definir este elemento real? É dizer, quais os limites de inserção destes valores ideais e reais no processo de interpretação? Estaria ocorrendo uma ultrapassagem de tais limites no caso apresentado neste trabalho?

A interpretação para ampliar o alcance da norma não é absoluta. Obviamente, e trabalhando com a hipótese do presente trabalho, não poderia o intérprete, em processo de aplicação da norma, criar ou ampliar de forma absoluta qualquer prestação previdenciária, sob o pretexto de garantir a subsistência e proteção do segurado.

A primeira análise deve partir da consideração da finalidade da norma, é dizer, para o que ela foi criada. A partir daí, fugindo de uma consideração absoluta do texto, ou sua falta, trabalhar com as hipótese que não estão abrangidas pela análise textual, mas que, se desconsideradas, efetivamente põem a norma em um estado de inefetividade. Considera-se, ainda, que a aplicação de uma norma constitucional impõe, ao menos em um primeiro momento, um conflito, geralmente instado entre o indivíduo e o Estado. 
Assim, com vistas a considerar a inserção de elementos sociais na norma, o intérprete deve averiguar a inteireza do ordenamento jurídico, levando em consideração toda a historicidade do direito, mesmo que irrepetíveis os respectivos eventos, com a construção dos paradigmas que consubstanciam o estágio atual. Esta atuação do julgador visa construir uma tutela jurisdicional constitucionalmente adequada ao paradigma do Estado Democrático de Direito (CARVALHO NETTO, 1998, p. 40).

Neste sentido, o conflito posto pela aplicação da norma constitucional garantidora reflete-se no interesse do Estado em proteger o Erário, ou mesmo garantir recursos para a manutenção do sistema de proteção previdenciária. A rigor, trata-se da manutenção do interesse público. De ver-se que este elemento não pode servir de barreira para efetivar uma garantia social, albergando o mínimo existencial. Afinal de contas, não basta que o Estado intervenha na economia, em busca do bem estar social mas, mais do que isso, é imperioso que seja conferido ao indivíduo um mínimo de força social e representatividade para que participe da vida política estatal (NOVAIS, 2006, p. 191)

Assim, na liberdade interpretativa do hermeneuta está o respeito aos valores essenciais definidos pela Ordem Constitucional vigente, que buscou garantir o social, com a reaproximação do Estado da sociedade, como forma de preservar a igualdade material. Não se deve, na análise da interpretação, criar mecanismos de defesa para a consecução de Direitos Sociais, em especial o direito à Previdência, sob o argumento de proteção ao erário, reserva do possível, in dubio pro societat, dentre outras construções. Assim deve ser pelo fato de que os Direitos Sociais já visam garantir e efetivar o mínimo que o cidadão deve dispor para uma vida digna, se houver retrocessos ou omissões, a dignidade resta prejudicada, não se preservando um dos fundamentos do Estado Brasileiro (SARLET, 2008, p. 23).

Como enfatiza Kildare Gonçalves (2002, p. 5):

\footnotetext{
As tensões entre a Constituição e a realidade constitucional, com a interpretação da Constituição de acordo com as leis, ou seja, de baixo para cima, o que é explicado como maneira de salvar a Constituição em face da pressão sobre ela exercida pelas complexas mudanças na realidade econômica e social, levam muitas vezes, na expressão de Canotilho, a mutações constitucionais quase imperceptíveis, o que pode resultar na formação de uma Constituição legal paralela, obtida por via interpretativa de desenvolvimento do Direito Constitucional e uma mutação constitucional inconstitucional.
}

Assim, o intérprete ao lado do dever de observar as conquistas sociais já alcançadas, em especial no âmbito previdenciário, deve trabalhar com o escopo real de aplicação da norma, é dizer, se existe uma relação de proteção insuficiente ou alguma situação que, embora não prevista no texto, deva ser abrangida pelos efeitos normativos, pois inclusa na norma, por mutação, diante da mudança da realidade, como forma de garantir a efetividade da Constituição. 
No que se refere ao questionamento acerca da ultrapassagem dos limites estabelecidos no processo interpretativo, a resposta a este questionamento encontra-se na conclusão, no sentido de que é possível e necessária a atribuição do adicional por invalidez no âmbito dos RPPSs dos Estados e Municípios brasileiros, independentemente de sua previsão legal nas leis específicas que regulamentam o regime, por aplicação da norma constitucional que combate o risco social da invalidez e por desdobramento da efetividade desta norma, através de inclusão expressa de tal adicional na norma infraconstitucional que regula o RGPS.

\section{CONSIDERAÇÕES FINAIS}

Assim, percebe-se que a ausência de norma, no âmbito de lei Estadual ou Municipal que institua RPPS, não impede efetividade de Direitos Fundamentais relacionados à Previdência Social, tanto em relação ao RGPS, como no que se refere ao RPPS, justamente pela aplicação da Dignidade da Pessoa Humana, que fundamenta a permite aplicação subsidiária do RGPS em face do RPPS, por dicção constitucional, atenta a universalidade de cobertura e do atendimento.

Mais uma situação que pode ser apresentada como de evidência do suprimento da ausência de texto expresso por aplicação da Dignidade da Pessoa Humana, para a efetivação de um Direito Fundamental, é o caso de ampliação do direito ao adicional de $25 \%$ para qualquer espécie de aposentadoria, no âmbito do RGPS. Esta possibilidade já vem sendo aceita pela jurisprudência consolidada da Turma Nacional de Uniformização dos Juizados Especiais, com base nos mesmos fundamentos aqui defendidos. Da mesma forma, o Supremo Tribunal Federal, sob o manto da proibição da proteção insuficiente dos riscos sociais, acolhe a possibilidade de ampliação dos instrumentos protetivos, ainda que não expressos em texto constitucional.

Todos os exemplos apresentados demonstram que a proteção social conferida ao fator de risco invalidez, presente no texto constitucional, abrange muito mais do que o estado incapacitante por parte do segurado, mas também o agravamento deste estado incapacitante, a ponto do segurado necessitar não somente do benefício de aposentadoria, mas também de um complemento, em decorrência da necessidade de acompanhamento por terceira pessoa, o que implica na impossibilidade de auferimento de renda pelo membro familiar que acompanha o segurado, prejudicando a subsistência da família.

Conclui-se, assim, que negar a máxima proteção social no presente caso é inviabilizar e rejeitar a intenção do constituinte, que foi elencar um instrumento de proteção ao risco 
social invalidez, tanto no âmbito da concessão da aposentadoria propriamente dita, como no âmbito do adicional de $25 \%$ sobre esta prestação previdenciária.

\section{REFERÊNCIAS}

ALEXY, Robert. Teoria dos Direitos Fundamentais, Malheiros, Traduzido por Virgílio Afonso da Silva (título original: Theorie der Grundrechte), 2015.

BARROSO, Luís Roberto. A dignidade da pessoa humana no direito constitucional contemporâneo: a construção de um conceito jurídico à luz da jurisprudência mundial; tradução Humberto Laport de Mello. - 3. reimpressão. - Belo Horizonte : Fórum, 2014, p. 66.

O Direito Constitucional e a Efetividade de suas normas, $5^{\text {a }}$ ed., Rio de Janeiro, Renovar, 2001.

BONAVIDES, Paulo. Curso de Direito Constitucional. São Paulo: Malheiros, 1997.

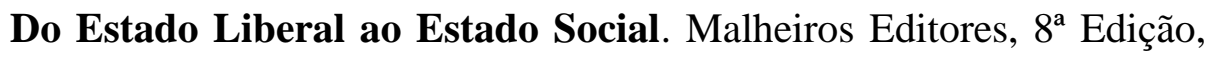

2007, São Paulo.

BONIFÁCIO, Artur Cortez. O Direito Constitucional Internacional e a proteção dos direitos fundamentais. São Paulo: Método, 2008.

BRASIL. Constituição Federal, de 05 de outubro de 1988, consultada realizada em 15 de dezembro de 2017 no link: http://www.planalto.gov.br/ccivil_03/constituicao/constituicaocompilado.htm.

Decreto $\mathrm{n}^{\circ} 6.949$, de 25 de agosto de 2009, consulta realizada em 15 de dezembro de 2017 no link: http://www.planalto.gov.br/ccivil_03/_ato20072010/2009/decreto/d6949.htm.

Lei Federal $\mathrm{n}^{\circ} 8.213$, de 24 de julho de 2991, consulta realizada em 15 de dezembro de 2017 no link: http://www.planalto.gov.br/ccivil_03/leis/l8213cons.htm.

, Lei Federal $\mathrm{n}^{\circ}$ 9.717, de 27 de novembro de 1998, consulta realizada em 15 de dezembro de 2017 no link: http://www.planalto.gov.br/ccivil_03/leis/L9717.htm. 
, Lei Complementar Federal $n^{\circ} 142$, de 08 de maio de 2013, consulta realizada em 15 de dezembro de 2017 no link: http://www.planalto.gov.br/ccivil_03/leis/LCP/Lcp142.htm.

SUPREMO TRIBUNAL FEDERAL. AgRg RE 385.397-0/MG. Recorrente: Instituto de Previdência dos Servidores do Estado de Minas Gerais. Recorrido: Antonio de Oliveira Rosa. Brasília/DF, Plenário, Rel. Min. Sepúlveda Pertence, julgado em. 29/06/07, consulta realizada em 15 de dezembro de 2017, no site http://www.stf.jus.br/portal/processo/verProcessoAndamento.asp?incidente=2118821.

SUPREMO TRIBUNAL FEDERAL. MI 758/DF. Impetrante: Carlos Humberto Marques. Impetrado: Presidente da República. Brasília/DF, Relator(a): Min. Marco Aurélio, Tribunal Pleno, julgado em 08/04/2010, consulta realizada em 15 de dezembro de 2017, $\quad$ no site http://www.stf.jus.br/portal/processo/verProcessoAndamento.asp?incidente=2530724.

SUPREMO TRIBUNAL FEDERAL. MI 4.475/DF. Impetrante: Sindicato dos Odontologistas de Minas Gerais. Impetrado: Presidente da República e Presidente do Congresso Nacional. Brasília/DF, Relator(a): Min. Ricardo Lewandowski, Julgamento Monocrático, julgado em 09/10/2013, consulta realizada em 15 de dezembro de 2017 no site http://www.stf.jus.br/portal/processo/verProcessoDetalhe.asp?incidente=4190708.

CARVALHO NETTO, Menelick de. A hermenêutica constitucional sob o paradigma do Estado Democrático de Direito. Notícia do Direito Brasileiro. Nova série $\mathrm{n}^{\circ}$ 6. Brasília: Ed. UnB, jul.-dez. de 1998, p. 233-250.

CARVELLI, Urbano; SCHOLL, Sandra. Evolução histórica dos Direitos Fundamentais: da antiguidade até as primeiras importantes declarações nacionais de direitos. Revista de Informação Legislativa: v. 48, n. 191 (jul./set. 2011).

CHAVES, Luciano Athayde. O Direito que "brota do chão"? Reflexões epistemológicas sobre a indução na ciência jurídica. Revista de Estudos Constitucionais, Hermenêutica e Teoria do Direito: RECHTD, v. 09, n 02, p. 151-166, maior-agosto de 2017.

COELHO, Paulo Magalhães da Costa. (2017). É possível a construção de uma hermenêutica constitucional emancipadora na pós-modernidade? Revista de Direito Constitucional e Internacional: RDCI, v. 13, n. 53, p. 7-19, out./dez. 2005.

COMPARATO, Fábio Konder. A afirmação histórica dos direitos humanos. $8^{\text {a }}$ Edição, 2013, São Paulo. 
GONÇALVES, Kildare. Interpretação constitucional. Revista do Tribunal de Contas do Estado de Minas Gerais, edição nº 03 de 2002, Ano XX.

GRIMM, Dieter. A Função Protetiva do Estado. In: SOUZA NETO, Cláudio Pereira; SARMENTO, Daniel. A Constitucionalização do Direito: Fundamentos Teóricos e Aplicações Específicas, Rio de Janeiro: Lúmen Júris, 2007.

HESSE, Konrad. A força normativa da constituição. Trad. Gilmar Ferreira Mendes. Porto Alegre: SAFe, 1991. 34 p. Este texto, originariamente, foi a base da aula inaugural que Hesse prolatou na Universidade de Frelburg (RFA), em 1959.

KANT, Immanuel. Metafísica dos Costumes. Editora Vozes,; tradução [primeira parte] Clélia Aparecida Martins, tradução [segunda parte] Bruno Nadai, Diego Kosbiau e Monique Hulshof. - Petrópolis, RJ: Vozes ; Bragança Paulista, SP : Editora Universitária São Francisco, 2013. - (Coleção Pensamento Humano).

LASSALE, Ferdinand. A essência da constituição. Trad Walter Stõnner. Rio de Janeiro: Ed. Liber Juris, 1985.49 p. Este texto, originariamente, foi apresentado em forma de Conferência que foi prolatada por Lassale em 1863 para intelectuais e operários da antiga Prússia.

MIRANDA, Jorge. Manual de Direito Constitucional, vol. IV, $3^{\text {a }}$ edição, Coimbra: Coimbra Editora, 2000.

NOVAIS, Jorge Reis. Contributo para uma teoria do Estado de direito. Coimbra: Almedina, 2006.

RIO GRANDE DO NORTE (Estado). Constituição do Estado, de 03 de outubro de 1989, consulta realizada em 15 de dezembro de 2017 no link: http://www2.senado.leg.br/bdsf/item/id/70437.

, Lei Complementar Estadual no 308, de 25 de outubro de 2005, consulta

$\begin{array}{lllllll}\text { realizada em } & 15 \text { de dezembro de } 2017 \text { no link }\end{array}$ http://adcon.rn.gov.br/acervo/IPERN/DOC/DOC000000000005235.PDF.

SARLET, Ingo Wolfgang. Proibição de Retrocesso, Dignidade da Pessoa Humana e Direitos Sociais: manifestação de um Constitucionalismo Dirigente possível. Revista Eletrônica Sobre Reforma do Estado, número 15 de set. a nov, Bahia, 2008. 
SAVARIS, José Antonio. Uma teoria da decisão judicial da Previdência Social: contributo para a superação da prática utilitarista; orientador Marcus Orione Gonçalves Correia; Tese (Doutorado) - Departamento de Direito do Trabalho e Previdência Social. Faculdade de Direito da Universidade de São Paulo - São Paulo, 2010;

SCHIER, Paulo Ricardo. A hermenêutica constitucional: instrumento para implementação de uma nova dogmática jurídica. Revista dos Tribunais, São Paulo, v. 86, n. 741 p. 38-57, jul. 1997.

SILVA, José Afonso da. Aplicabilidade das Normas Constitucionais. 5 $5^{\text {a }}$ Ed. Malheiros, 2001

THE MAXIMUM SOCIAL PROTECTION AND FUNDAMENTAL RIGHTS: THE

CASE OF THE GREAT INVALIDITY IN THE OWN REGIME OF THE RIO

GRANDE DO NORTE STATE

\begin{abstract}
Social protection is essential for ensuring equality without relationships between relationships and between them and the State. In this sense, a Social Security, as an integral element of Social Security, engenders the protective framework of the individual facing more diverse risks in society. Faced with this panorama, it is imperative to confer maximum effectiveness of these rights, since they are related to the existential minimum of the individual, being essential for the guarantee of equality. Thus, the present work, through analytical bibliographical research, aims to demonstrate the need for maximum social protection, recognizing a direct application of the Constitution in cases in which there is a legislative omission. As a way of demonstrating this need, the study of the situation of the disability allowance in the pensions foreseen in Private Pension Schemes should be used, when there is no express provision for this additional amount, demonstrating that it is possible, through the application of the Constitution itself, of this right to the RPPS policyholders.
\end{abstract}

Keywords: Additional for disability. Maximum Social Protection. Social Security. Own Regime. 